\title{
On Similarity of Seismo Magnetic Power Density and Pressure Head Fractal Dimension for Characterizing Shajara Reservoirs of the Permo-Carboniferous Shajara Formation, Saudi Arabia
}

\section{Khalid Elyas Mohamed Elameen Alkhidir}

Professor, Department of Petroleum and Natural Gas Engineering, College of Engineering, King Saud University, Saudi Arabia

\begin{abstract}
The quality and assessment of a reservoir can be documented in details by the application of seismo magnetic power density. This research aims to calculate fractal dimension from the relationship among seismo magnetic power density, maximum seismo magnetic power density and wetting phase saturation and to approve it by the fractal dimension derived from the relationship among inverse pressure head ${ }^{*}$ pressure head and wetting phase saturation. Two equations for calculating the fractal dimensions have been employed. The first one describes the functional relationship between wetting phase saturation, seismo magnetic power density, maximum seismo magnetic power density and fractal dimension. The second equation implies to the wetting phase saturation as a function of pressure head and the fractal dimension. Two procedures for obtaining the fractal dimension have been utilized. The first procedure was done by plotting the logarithm of the ratio between seismo magnetic power density and maximum seismo magnetic power density versus logarithm wetting phase saturation. The slope of the first procedure $=3$ - Df (fractal dimension). The second procedure for obtaining the fractal dimension was determined by plotting the logarithm (inverse of pressure head and pressure head) versus the logarithm of wetting phase saturation. The slope of the second procedure $=\mathrm{Df}-3$. On the basis of the obtained results of the fabricated stratigraphic column and the attained values of the fractal dimension, the sandstones of the Shajara reservoirs of the Shajara Formation were divided here into three units.
\end{abstract}

Corresponding author: Prof. Khalid Elyas Mohamed Elameen Alkhidir, Ph.D. Department of Petroleum and Natural Gas Engineering, College of Engineering, King Saud University, Saudi Arabia, Email: kalkhidir@ksu.edu.sa

Received: February 16, 2020 Accepted: February 24, 2020, Published: February 28, 2020

Keywords: Shajara Reservoirs, Shajara Formation, Seismo Magnetic Power Density Fractal Dimension, Pressure Headfractal Dimension, Permeability

\section{Introduction}

Seismo electric effects related to electro kinetic potential, dielectric permitivity, pressure gradient, fluid viscosity, and electric conductivty was first reported by [1].
Capillary pressure follows the scaling law at low wetting phase saturation was reported by [2]. Seismo electric phenomenon by considering electro kinetic coupling coefficient as a function of effective charge density, 
permeability, fluid viscosity and electric conductivity was reported by [3]. The magnitude of seismo electric current depends on porosity, pore size, zeta potential of the pore surfaces, and elastic properties of the matrix was investigated by [4]. The tangent of the ratio of converted electic field to pressure is approximately in inverse proportion to permeability was studied by [5]. Permeability inversion from seismoelectric log at low frequency was studied by [6]. They reported that, the tangent of the ratio among electric excitation intensity and pressure field is a function of porosity, fluid viscosity, frequency, tortuosity and fluid density and Dracy permeability. A decrease of seismo electric frequencies with increasing water content was reported by [7]. An increase of seismo electric transfer function with increasing water saturation was studied by [8]. An increase of dynamic seismo electric transfer function with decreasing fluid conductivity was described by [9]. The amplitude of seismo electric signal increases with increasing permeability which means that the seismo electric effects are directly related to the permeability and can be used to study the permeability of the reservoir was illustrated by [10]. Seismo electric coupling is frequency dependent and decreases expontialy when frequency increases was demonstrated by [11]. An increase of permeability with increasing seismo magnetic moment and seismo diffusion coefficiernt fractal dimension was reported by $[12,13]$. An increase of, molar enthalpy, work, electro kinetic, bubble pressure and pressure head fractal dimensions with permeability increasing and grain size was described by $[14,15,16,17]$.

\section{Material and Methods}

Sandstone samples were collected from the surface type section of the Permo-Carboniferous Shajara Formation, latitude $26^{\circ} 52^{\prime} 17.4^{\prime \prime}$, longitude $43^{\circ} 36^{\prime} 18^{\prime \prime}$. (Figure 1). Porosity was measured on collected samples using mercury intrusion Porosimetry and permeability was derived from capillary pressure data. The purpose of this paper is to obtain seismo magentic power density fractal dimension and to confirm it by capillary pressure fractal dimension. The fractal dimension of the first procedure is determined from the positive slope of the plot of logarithm of the ratio of seismo magentic power density to maximum seismo magentic power density $\log$ (SMPD1/4/SMPD1/4max) versus log wetting phase saturation $(\log S w)$. Whereas the fractal dimension of the second procedure is determined from the negative slope of the plot of logarithm of log capillary pressure (log Pc) versus logarithm of wetting phase saturation (log Sw).

The Seismo magentic power density can be scaled as
$\mathbf{S w}=\left[\frac{\mathbf{S M P D}^{\frac{1}{4}}}{\mathbf{S M P D}_{\max }^{\frac{1}{4}}}\right]^{[3-\mathrm{Df}]}$

Where Sw the water saturation, SMPD the seismo magentic power density in vott ${ }^{*}$ second / square meter, SMPDmax the maximum seismo magentic power density in vott ${ }^{*}$ second / square meter, and Df the fractal dimension.

Equation 1 can be proofed from

$\mathbf{H}=\left[\begin{array}{cc}\phi^{*} \epsilon * \mathbf{k f} \tilde{\mathbf{n}}{ }^{*} \mathbf{S S W} \mathbf{W} & \mathbf{S R G} \mathbf{G V} \\ \hline \mathbf{a} \infty * \mathbf{c}\end{array}\right]$

2

Where $\mathrm{H}$ the magnetic field in ampere / meter, $\phi$ the porosity, $€$ the fluid permittivity in Faraday / meter, kf the fluid dielectric constant, the fluid density Pf in kilogram / cubic meter, SSWV the seismic shear wave velocity in meter / second, SRGV the seismo magentic power density in meter / second, $\alpha$ the tortuosity, $\eta$ the fluid viscosity in pascal ${ }^{*}$ second

The seismo magnetic field $\mathrm{H}$ can be scaled as

$$
\mathbf{H}=\left[\frac{\mathrm{SEC}}{\mathbf{d}}\right]
$$

Where $\mathrm{H}$ the seismo magnetic field in ampere / meter, SEC the seismo electric current in ampere, and $d$ the distance in meter

Insert equation 3 into equation 2

$$
\left[\frac{S E C}{d}\right]=\left[\frac{\phi * \in * k f * \zeta * p f * S S W V * S R G V}{\alpha \infty * \eta}\right]
$$

The seismo electric current SEC can be scaled as

$$
\mathrm{SEC}=\left[\frac{\mathrm{SEP}}{\mathrm{R}}\right]
$$

Where SEC the seismo electric current in ampere, SEP the seismo electric potential in volt, and $\mathrm{R}$ the resistance in ohm

Insert equation 5 into equation 4

$$
\left[\frac{S E P}{d * R}\right]=\left[\frac{\phi * \in * k f * \zeta * p f * S S W V * S R G V}{\alpha \infty * \eta}\right]
$$


The seismo electric potential can be scaled

SEP $=\left[\frac{\text { SMP }}{\text { ST }}\right]$

Where SEP the seismo electric potential in volt, SMP the seismo magentic power in volt ${ }^{*}$ second, ST the seismic time Insert equation 7 into equation 6

$\left[\frac{S M P}{d * R * S T}\right]=\left[\frac{\phi * \in * k f * \zeta * p f * S S W V * S R G V}{\alpha \infty * \eta}\right]$

The seismo magnetic power can be scaled as

$\mathbf{S M P}=\mathbf{S M P D} * \mathbf{A}$

Where SMP the seismo magnetic power in volt * second, SMPD the seismo magentic power density in volt * second / square meter, and $\mathrm{A}$ the area in square meter

Insert equation 9 into equation 8

$\left[\frac{S M P D * A}{d * R * S T}\right]=\left[\frac{\phi * \in * k f * \zeta * p f * S S W V * S R G V}{\alpha \infty * \eta}\right]$

The viscosity $\eta$ can be scaled as

$\eta=\mathrm{p}^{\star} \mathrm{t}$

Where $\eta$ the fluid viscosity in pascal ${ }^{*}$ second, $p$ the pressure in pascal, and $t$ the time in second Insert equation 11 into equation 12

$\left[\frac{S M P D * A}{d * R * S T}\right]=\left[\frac{\left(\grave{e} * * k f * \mathbf{q} *^{2} f * S S W V * S R G V * Q\right.}{\neg^{*} \mathrm{p} * t}\right]$

The time $t$ can be scaled as

$\mathbf{t}=\left[\frac{\mathbf{V}}{\mathbf{Q}}\right]$

Where $\mathrm{t}$ the time in second, $\mathrm{V}$ the volume in cubic meter, $\mathrm{Q}$ the flow rate in cubic meter / second

Insert equation 13 into equation 12

$\left[\frac{S M P D * A}{d * R * S T}\right]=\left[\frac{\left(\grave{e} * * k f * \boldsymbol{\Phi} *^{2} f * S S W V * S R G V * Q\right)}{\left(\neg{ }^{*} \mathrm{p} * V\right)}\right]$ 14

The flow rate can be scaled as

$$
Q=\left[\frac{3.14 * r^{4} * \Delta p}{8 * \eta * L}\right] 15
$$

Where Q the flow rate in cubic meter / second, $\mathrm{r}$ the pore radius in meter, $\Delta \mathrm{p}$ the differential pressure in pascal, $\eta$ the fluid viscosity in pascal * second, L the capillary length in meter.

Insert equation 15 into equation 14

$\left[\frac{S M P D * A}{d * R * S T}\right]=\left[\frac{\phi * \in * k f * \zeta * p f * S S W V * S R G V * 3.14 * r * \Delta p}{\alpha \infty * p * V * 8 * \eta * L}\right]$ 16

The mximum pore radius rmax can be scaled as

$\left[\frac{S M P D_{\max } * A}{d * R * S T}\right]=\left[\frac{\phi * \in * k f * \zeta * p f * S S W V * S R G V * 3.14 * r_{\max }^{4} * \Delta p}{\alpha \infty * p * V * 8 * \eta * L}\right]$ 17

Divide equation 16 by equation 17

$\frac{\left[\frac{S M P D * A}{d * R * S T}\right]=\left[\frac{\phi * \in * k f * \zeta * p f * S S W V * S R G V * 3.14 * r * \Delta p}{\alpha \infty * p * V * 8 * \eta * L}\right]}{\left[\frac{S M P D_{\max } * A}{d * R * S T}\right]=\left[\frac{\phi * \in * k f * \zeta * p f * S S W V * S R G V * 3.14 * r_{\max }^{4} * \Delta p}{\alpha \infty * p * V * 8 * \eta * L}\right]} 18$

Equation 18 after simplification will become

$\left[\frac{\text { SMPD }}{\text { SMPD }_{\max }}\right]=\left[\frac{\mathbf{r}^{4}}{\mathbf{r}_{\max }^{4}}\right]$

Take the fourth root of equation 19

$\sqrt[4]{\left[\frac{\mathbf{S M P D}}{\mathbf{S M P D}}\right]}=\sqrt[4]{\left[\frac{\mathbf{r}_{\text {max }}^{4}}{\mathbf{r}_{\text {max }}^{4}}\right]}$

Take the logarithm of equation 21 


\section{$\log \left[\frac{\mathbf{S M P D}^{\frac{1}{4}}}{\mathbf{S M P D}_{\max }^{\frac{1}{4}}}\right]=\log \left[\frac{\mathbf{r}}{\mathbf{r}_{\text {max }}}\right]$}

$$
\text { But; } \log \left[\frac{\mathbf{r}}{\mathbf{r}_{\max }}\right]=\left[\frac{\log \mathbf{S w}}{3-\mathbf{D f}}\right]
$$

Insert equation 23 into equation 22

$$
\left[\frac{\log \mathbf{S w}}{3-\mathbf{D f}}\right]=\log \left[\frac{\mathbf{S M P D}^{\frac{1}{4}}}{\mathbf{S M P D}_{\max }^{\frac{1}{4}}}\right]
$$

Equation 24 after log removal will become

$$
\mathbf{S w}=\left[\frac{\mathbf{S M P D}^{\frac{1}{4}}}{\mathbf{S M P D}_{\max }^{\frac{1}{4}}}\right]^{[3-\mathrm{Df}]}
$$

Equation 25 the proof of equation 1 which relates the water saturation, seismo magentic power density, maximum seismo magentic power density, and the fractal dimension. The capillary pressure can be scaled as

$$
\log S w=[D f-3] * \log (\alpha * h)+\text { constant }
$$

Where Sw the water saturation, $a$ inverse of pressure head, $h$ the pressure head and Df the fractal dimension.

\section{Results and Discussion}

Based on field observation the Shajara Reservoirs of the Permo-Carboniferous Shajara Formation were divided here into three units as described in Figure1.These units from bottom to top are: Lower Shajara Reservoir, Middle Shajara reservoir, and Upper Shajara Reservoir. Their attained results of the seismo magnetic power density fractal dimension and pressure head fractal dimension are shown in Table 1. Based on the achieved results it was found that the seismo magnetic power density fractal dimension is equal to the pressure head fractal dimension. The maximum value of the fractal dimension was found to be 2.7872 allocated to sample SJ13 from the Upper Shajara Reservoir as verified in Table 1. Whereas the minimum value of the fractal dimension 2.4379 was reported from sample SJ3 from the Lower Shajara reservoir as shown in Table1. The Seismo magnetic power density fractal dimension and pressure head fractal dimension were detected to increase with increasing permeability as proofed in Table1 owing to the possibility of having interconnected channels. The Lower Shajara reservoir was symbolized by six sandstone samples (Figure 1), four of which label as SJ1, SJ2, SJ3 and SJ4 were carefully chosen for capillary pressure measurement as proven in Table1. Their positive slopes of the first procedure log of the Seismo magnetic power density to maximum Seismo magnetic power density versus log wetting phase saturation (Sw) and negative slopes of the second procedure log (inverse of pressure head $\alpha^{\star}$ pressure head $h$ ) versus log wetting phase saturation $(\mathrm{Sw})$ are clarified in Figure 2, Figure 3, Figure 4, Figure 5 and Table 1. Their Seismo magnetic power density fractal dimension and pressure head fractal dimension values are revealed in Table 1. As we proceed from sample SJ2 to SJ3 a pronounced reduction in permeability due to compaction was described from 1955 md to 56 md which reflects decrease in Seismo magnetic power density fractal dimension from 2.7748 to 2.4379 as quantified in table 1 . Again, an increase in grain size and permeability was proved from sample SJ4 whose seismo magnetic power density fractal dimension and pressure head fractal dimension was found to be 2.6843 as described in Table 1 . In contrast, the Middle Shajara reservoir which is separated from the Lower Shajara reservoir by an unconformity surface as revealed in Figure 1. It was nominated by four samples (Figure 1), three of which named as SJ7, SJ8, and SJ9 as illuminated in Table1 were chosen for capillary measurements as described in Table 1. Their positive slopes of the first procedure and negative slopes of the second procedure are shown in Figure 6, Figure 7 and Figure 8 and Table 1. Furthermore, their Seismo magnetic power density fractal dimensions and pressure head fractal dimensions show similarities as defined in Table 1. Their fractal dimensions are higher than those of samples SJ3 and SJ4 from the Lower Shajara Reservoir due to an increase in their permeability as explained in table 1 . On the other hand, the Upper Shajara reservoir was separated from the Middle Shajara reservoir by yellow green mudstone as shown in Figure 1. It is defined by three samples so called SJ11, SJ12, SJ13 as explained in Table 1. Their positive slopes of the first procedure and negative slopes of the second procedure are displayed in Figure 9, Figure 10 and Figure 11 and Table 1. Moreover, their seismo magnetic power density 
Citation: Elameen Alkhidir KEM (2020)On Similarity of Seismo Magnetic Power Density and Pressure Head Fractal Dimension for Characterizing Shajara Reservoirs of the Permo-Carboniferous Shajara Formation, Saudi Arabia. Journal of Physics \& Optics Sciences. SRC/JPSOS/109. DOI: doi.org/10.47363/JPSOS/2020(2)105

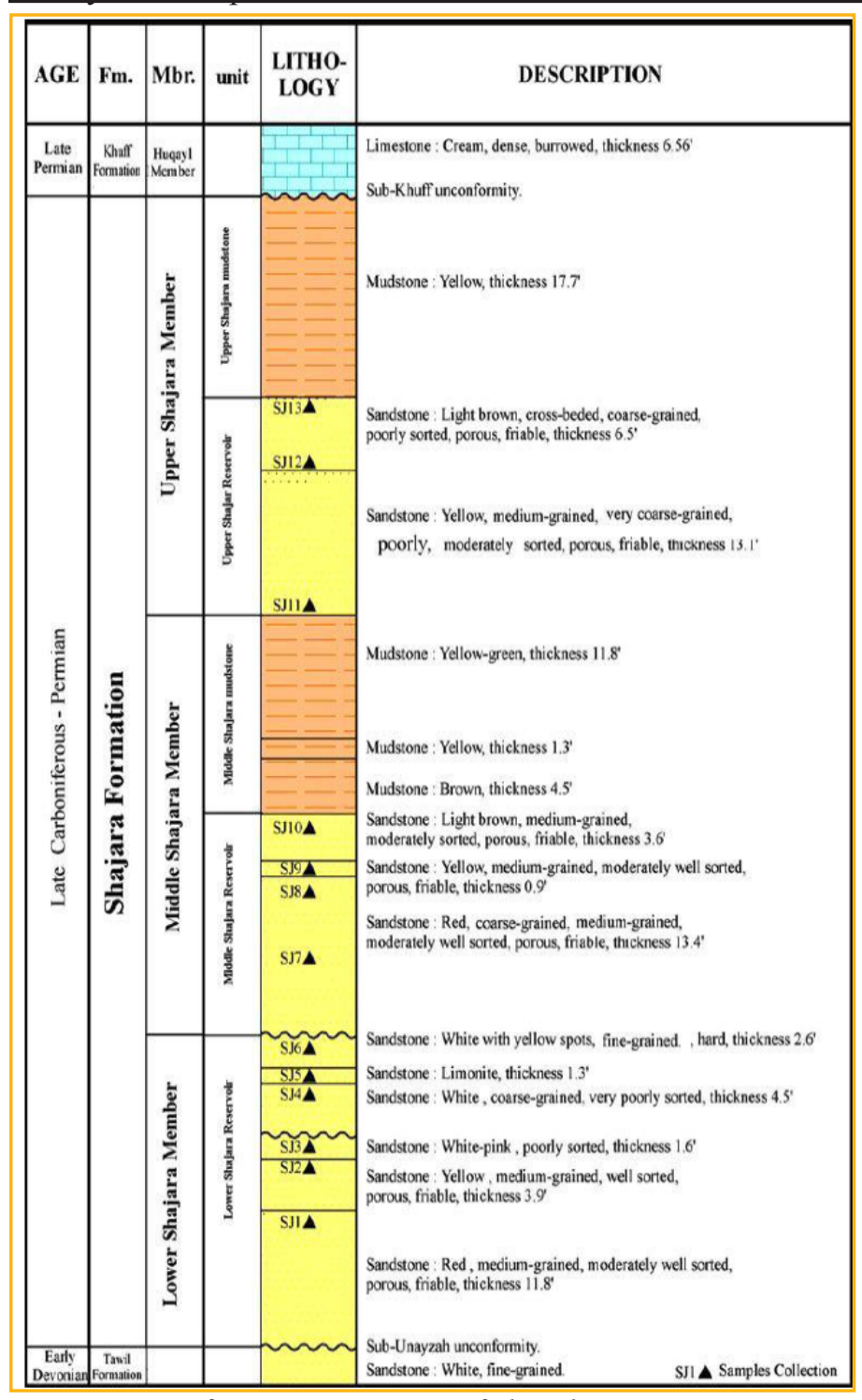

Figure 1: Surface type section of the Shajara Reservoirs of the Permo-Carboniferous Shajara Formation at latitude $26^{\circ} 52^{\prime} 17.4^{\prime \prime}$ longitude $43^{\circ} 36^{\prime} 18^{\prime \prime}$.

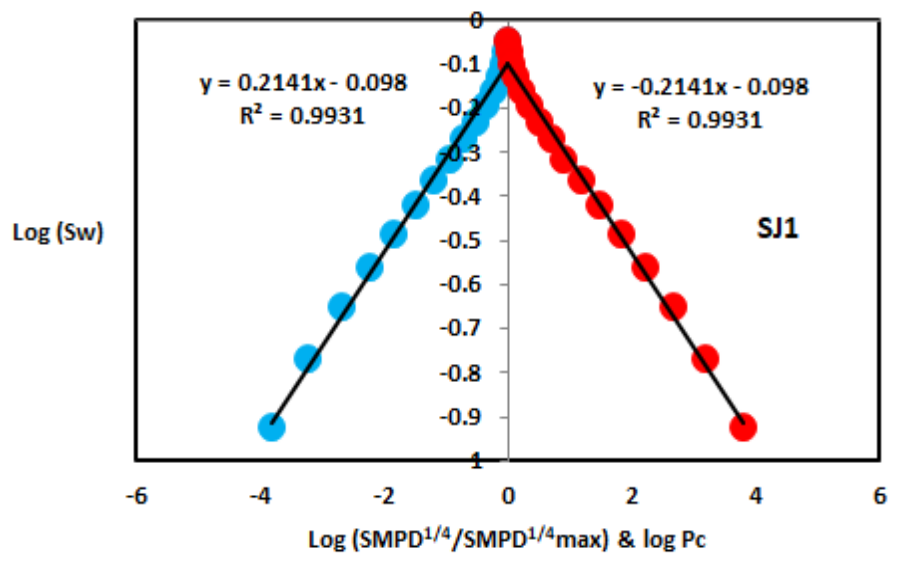

Figure 2: $\log (\mathrm{SMPD} 1 / 4 / \mathrm{SMPD} 1 / 4 \max ) \& \log \left(\alpha^{*} \mathrm{~h}\right)$ versus $\log$ Sw for sample SJ1.

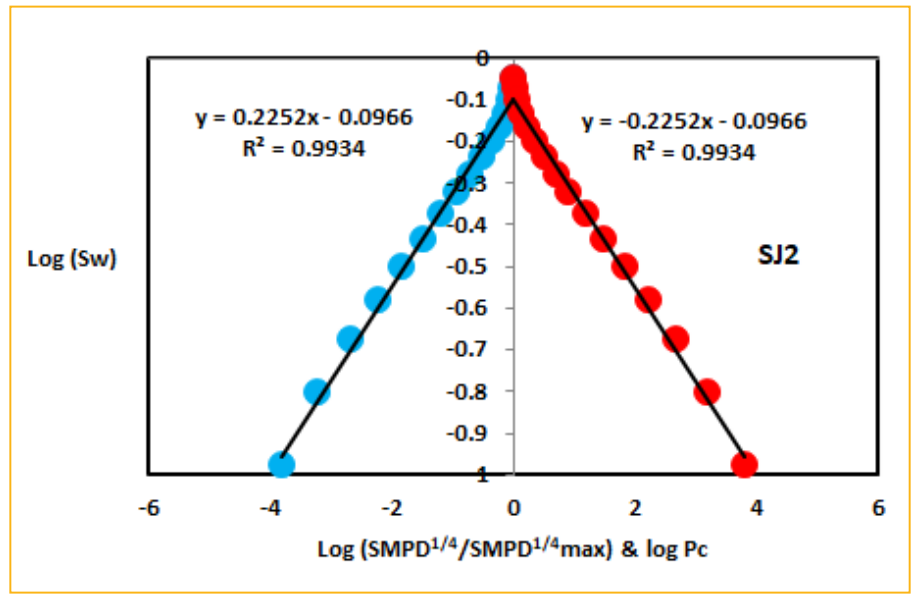

Figure 3: $\log \left(\right.$ SMPD1/4/SMPD1/4max) \& $\log \left(\alpha^{*} h\right)$ versus $\log$ Sw for sample SJ2.

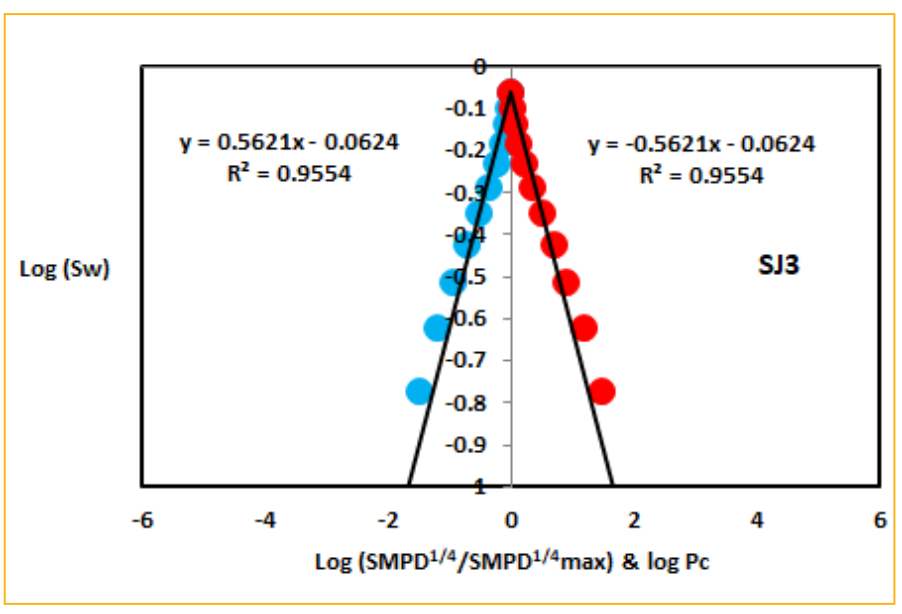

Figure 4: $\log (\mathrm{SMPD} 1 / 4 / \mathrm{SMPD} 1 / 4 \max ) \& \log \left(\alpha^{\star} h\right)$ versus $\log$ Sw for sample SJ3.

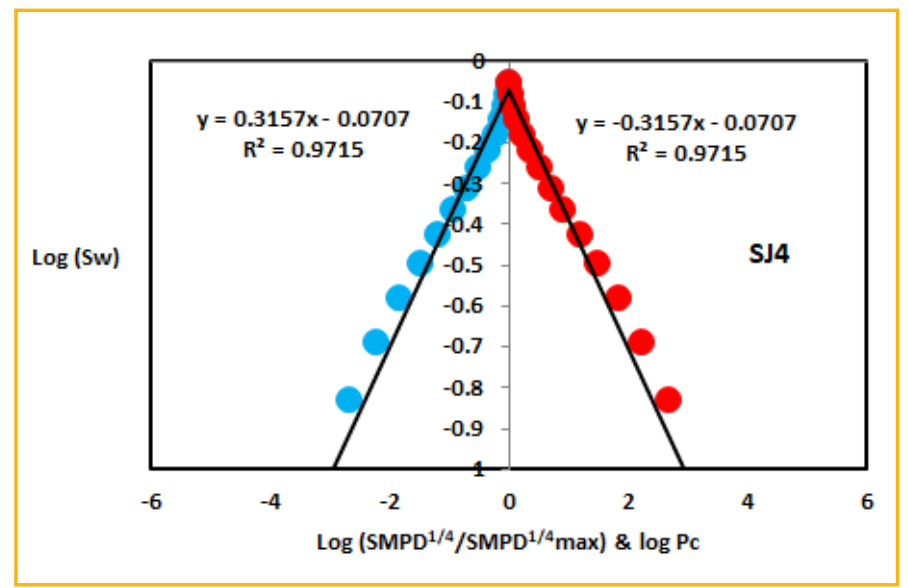

Figure 5: $\log ($ SMPD1/4/SMPD1/4max $) \& \log \left(\alpha^{*} h\right)$ versus $\log$ Sw for sample SJ4. 


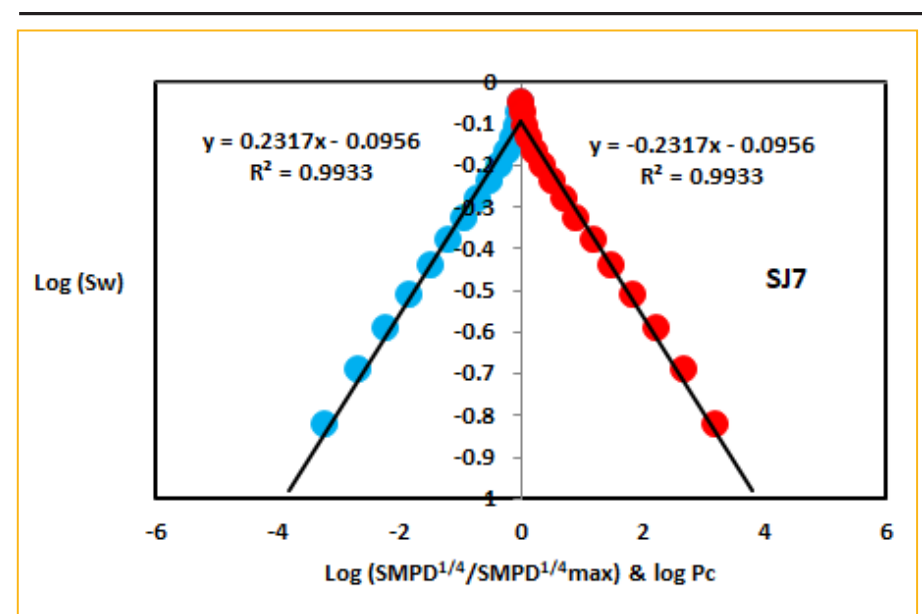

Figure 6: $\log \left(\mathrm{SMPD}^{1 / 4} / \mathrm{SMPD}_{\max }^{1 / 4}\right) \& \log \left(\alpha^{\star} \mathrm{h}\right)$ versus $\log$ Sw for sample SJ7.

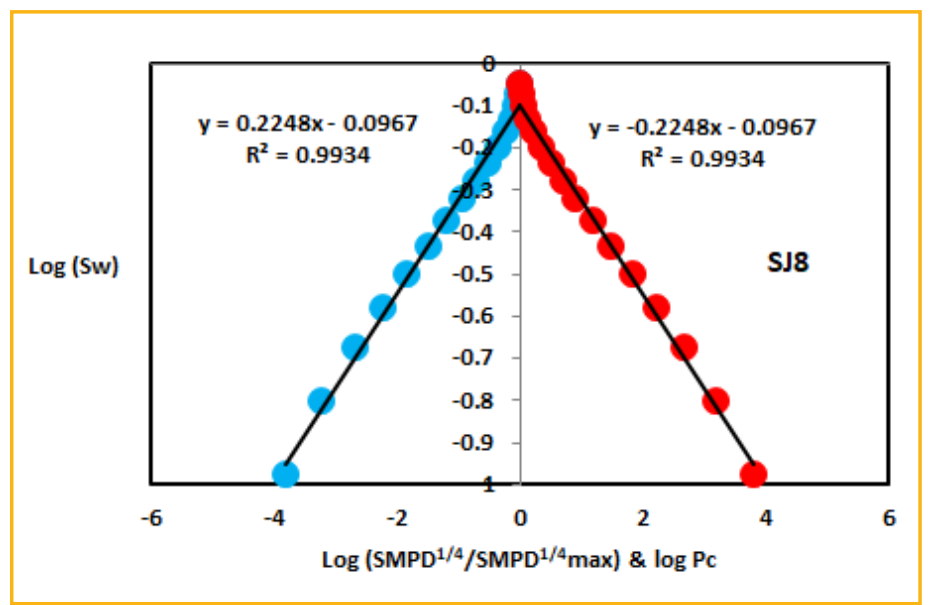

Figure 7: $\log \left(\mathrm{SMPD}^{1 / 4} / \mathrm{SMPD}_{\text {max }}^{1 / 4}\right) \& \log \left(\alpha^{*} \mathrm{~h}\right)$ versus $\log$ Sw for sample SJ8.

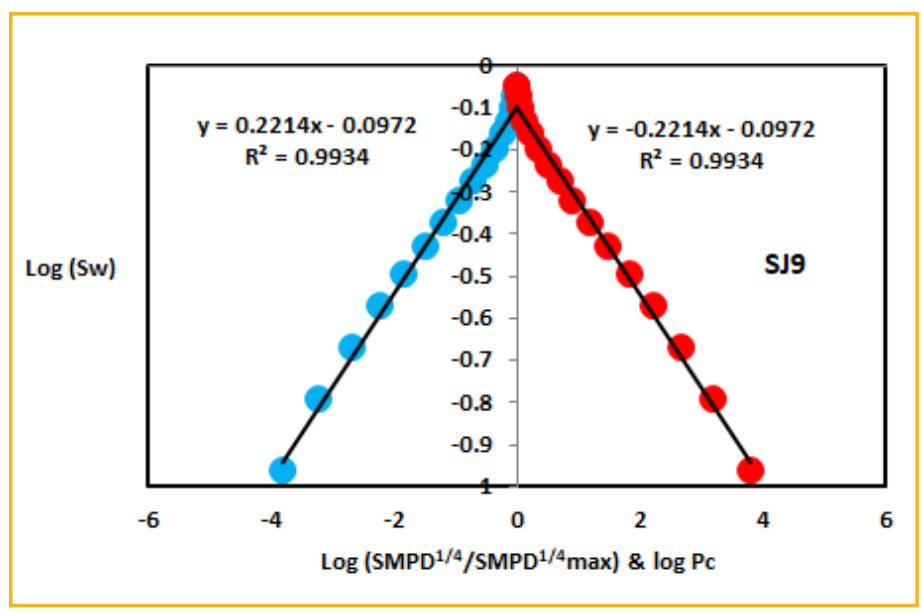

Figure 8: $\log (\operatorname{SMPD} 1 / 4 / \mathrm{SMPD} 1 / 4 \max ) \& \log \left(\alpha^{*} \mathrm{~h}\right)$ versus $\log$ Sw for sample SJ9.

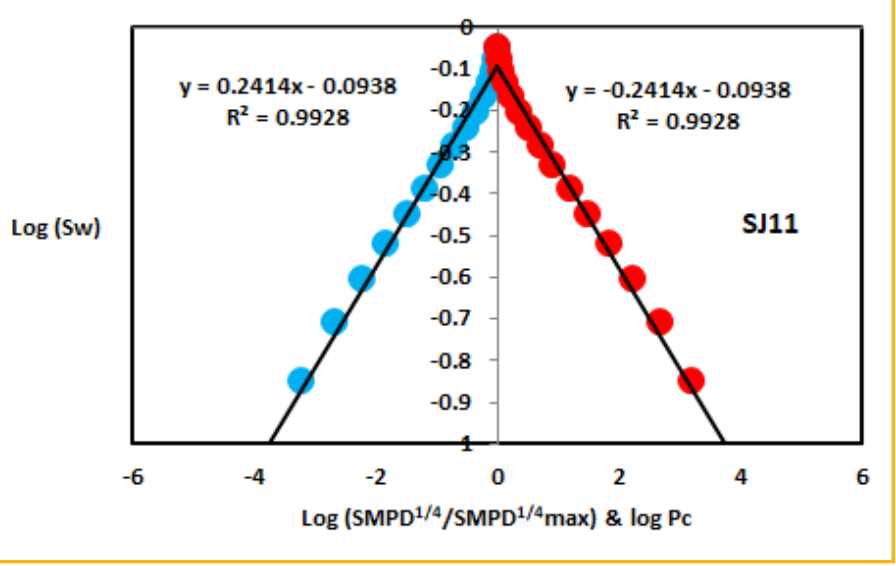

Figure 9: $\log (\mathrm{SMPD} 1 / 4 / \mathrm{SMPD} 1 / 4 \max ) \& \log \left(\alpha^{*} \mathrm{~h}\right)$ versus $\log$ Sw for sample SJ11.

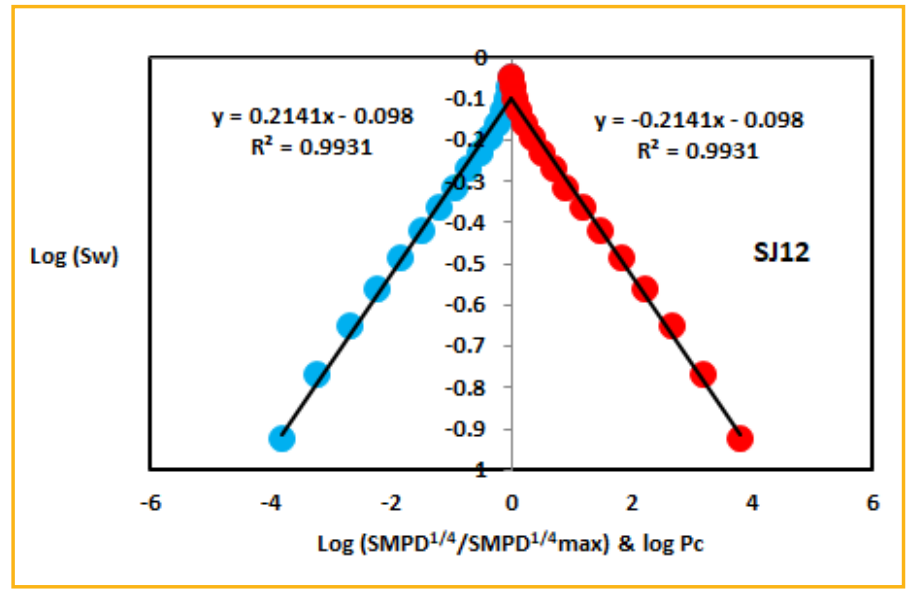

Figure 10: $\log (\mathrm{SMPD} 1 / 4 / \mathrm{SMPD} 1 / 4 \max ) \& \log \left(a^{*} \mathrm{~h}\right)$ versus $\log$ Sw for sample SJ12.

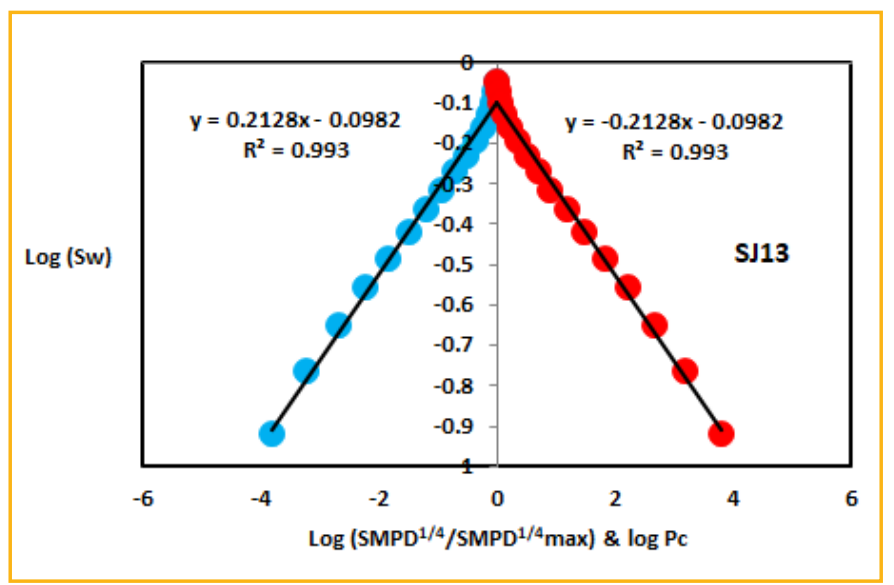

Figure 11: $\log (\mathrm{SMPD} 1 / 4 / \mathrm{SMPD} 1 / 4 \max ) \& \log \left(\alpha^{*} \mathrm{~h}\right)$ versus log Sw for sample SJ13. 


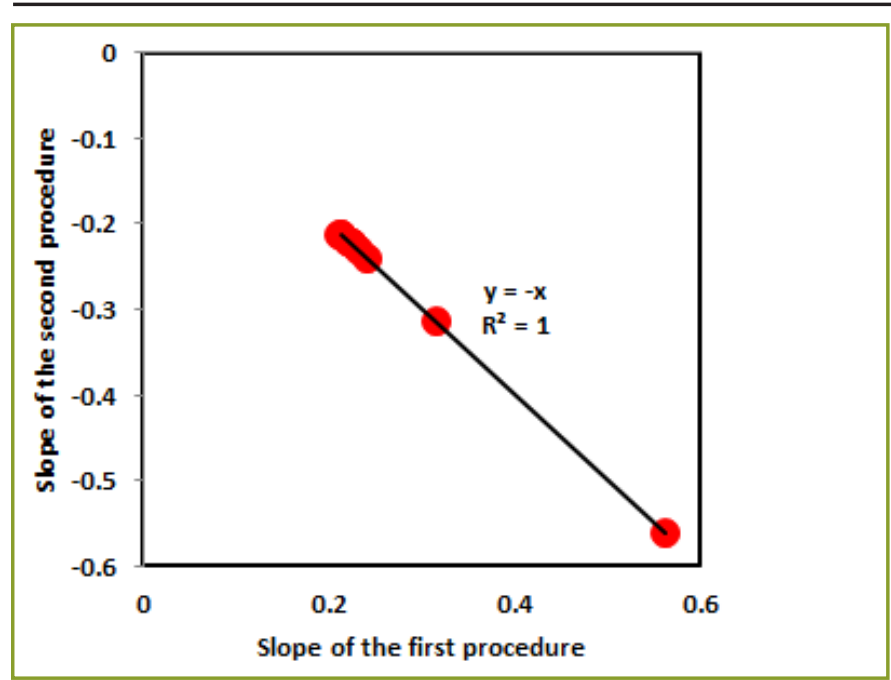

Figure 12: Slope of the first procedure versus slope of the second procedure.

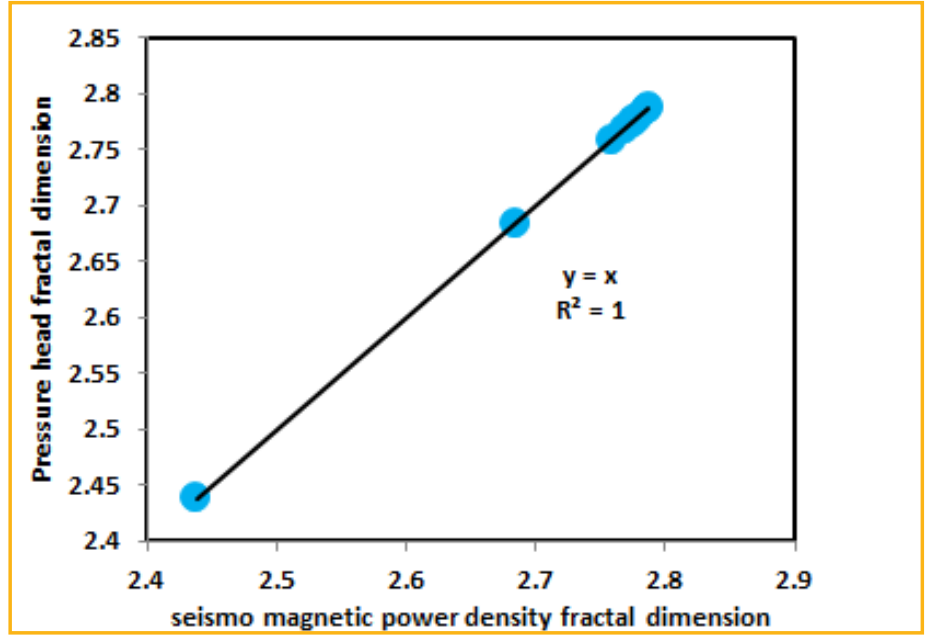

Figure 13: Seismo magnetic power density fractal dimension versus pressure headfractal dimension.

\begin{tabular}{|c|c|c|c|c|c|c|c|c|}
\hline $\begin{array}{l}\text { Forma- } \\
\text { tion }\end{array}$ & Reservoir & Sample & $\begin{array}{l}\text { Porosity } \\
\%\end{array}$ & $\begin{array}{l}\mathbf{k} \\
\text { (md) }\end{array}$ & $\begin{array}{l}\text { Positive } \\
\text { slope of the } \\
\text { first proce- } \\
\text { dure } \\
\text { Slope=3-Df }\end{array}$ & $\begin{array}{l}\text { Negative } \\
\text { slope of } \\
\text { the second } \\
\text { procedure } \\
\text { Slope=Df-3 }\end{array}$ & $\begin{array}{l}\text { Seismo } \\
\text { magnetic } \\
\text { power den- } \\
\text { sity fractal } \\
\text { dimension }\end{array}$ & $\begin{array}{l}\text { Pressure } \\
\text { head frac- } \\
\text { tal dimen- } \\
\text { sion }\end{array}$ \\
\hline \multirow{10}{*}{\begin{tabular}{l|} 
Per- \\
mo-Car- \\
boniferous \\
Shajara \\
Formation
\end{tabular}} & \multirow{3}{*}{\begin{tabular}{|l|} 
Upper \\
Shajara \\
Reservoir
\end{tabular}} & SJ13 & 25 & 973 & 0.2128 & -0.2128 & 2.7872 & 2.7872 \\
\hline & & SJ12 & 28 & 1440 & 0.2141 & -0.2141 & 2.7859 & 2.7859 \\
\hline & & SJ11 & 36 & 1197 & 0.2414 & -0.2414 & 2.7586 & 2.7586 \\
\hline & \multirow{3}{*}{$\begin{array}{l}\text { Middle } \\
\text { Shajara } \\
\text { Reservoir }\end{array}$} & SJ9 & 31 & 1394 & 0.2214 & -0.2214 & 2.7786 & 2.7786 \\
\hline & & SJ8 & 32 & 1344 & 0.2248 & -0.2248 & 2.7752 & 2.7752 \\
\hline & & SJ7 & 35 & 1472 & 0.2317 & -0.2317 & 2.7683 & 2.7683 \\
\hline & \multirow{4}{*}{$\begin{array}{l}\text { Lower } \\
\text { Shajara } \\
\text { Reservoir }\end{array}$} & SJ4 & 30 & 176 & 0.3157 & -0.3157 & 2.6843 & 2.6843 \\
\hline & & SJ3 & 34 & 56 & 0.5621 & -0.5621 & 2.4379 & 2.4379 \\
\hline & & SJ2 & 35 & 1955 & 0.2252 & -0.2252 & 2.7748 & 2.7748 \\
\hline & & SJ1 & 29 & 1680 & 0.2141 & -0.2141 & 2.7859 & 2.7859 \\
\hline
\end{tabular}

Table 1: Petrophysical model showing the three Shajara Reservoir Units with their corresponding values of seismo magnetic power density fractal dimension and pressure head fractal dimension. 
fractal dimension and pressure head fractal dimension are also higher than those of sample SJ3 and SJ4 from the Lower Shajara Reservoir due to an increase in their permeability as simplified in table 1. Overall a plot of positive slope of the first procedure versus negative slope of the second procedure as described in Figure 12 reveals three permeable zones of varying Petrophysical properties. These reservoir zones were also confirmed by plotting seismo magnetic power density fractal dimension versus pressure head fractal dimension as described in Figure 13. Such variation in fractal dimension can account for heterogeneity which is a key parameter in reservoir quality assessment.

\section{Conclusion}

The sandstones of the Shajara Reservoirs of the permoCarboniferous Shajara Formation were divided here into three units based on seismo magnetic power density fractal dimension. The Units from base to top are: Lower Shajara Seismo Magnetic Power Density Fractal Dimension Unit, Middle Shajara Seismo Magnetic Power Density Fractal Dimension Unit, and Upper Shajara Seismo Magnetic Power Density Fractal Dimension Unit. These units were also proved by pressure head fractal dimension. The fractal dimension was found to increase with increasing grain size and permeability owing to possibility of having interconnected channels.

\section{Acknowledgement}

The author would to thank King Saud University, college of Engineering, Department of Petroleum and Natural Gas Engineering, Department of Chemical Engineering, Research Centre at College of Engineering, College of science, Department of Geology, and King Abdullah Institute for research and Consulting Studies for their supports.

\section{References}

1. Frenkel J (1944) On the theory of seismic and seismoelectric phenomena in a moist soil. Journal of physics 3: 230-241.

2. Li K, Williams W (2007) Determination of pressure head function from resistivity data. Transport in Porous Media 67: 1-15.

3. Revil A, Jardani A (2010) Seismo electric response of heavy oil reservoirs: theory and numerical modelling. Geophysical Journal International 180: 781-797.

4. Dukhin A, Goetz P, Thommes M (2010) Seismoelectric effect: a non-isochoric streaming current.1 Experiment. Journal of Colloid and Interface Science 345: 547-553.

5. Guan W, Hu H, Wang Z (2012) Permeability inversion from low-frequency seismoelectric logs in fluid- saturated porous formations. Geophysical Prospecting 61: 120-133.

6. Hu H, Guan W, Zhao W (2012) Theoretical studies of permeability inversion from seismoelectric logs. Geophysical Research Abstracts 14, EGU2012-6725-1 2012 EGU General Assembly.

7. Borde $\mathrm{C}, \mathrm{S}$ en echal P Barri ere J, Brito D, Normandin E, (2015) Impact of water saturation on seismoelectric transfer functions: a laboratory study of co-seismic phenomenon. Geophysical J International 200: 1317-1335.

8. Jardani A, Revil A (2015) Seismoelectric couplings in a poroelastic material containing two immiscible fluid phases. Geophysical Journal International 202: 850-870.

9. Holzhauer J, Brito D, Bordes C, Brun Y, Guatarbes B (2016) Experimental quantification of the seismoelectric transfer function and its dependence on conductivity and saturation in loose sand. Geophysical Prospecting 65: 1097-1120

10. Rong Peng, Jian-Xing Wei, Bang-Rang Di, Pin-Bo Ding, ZiChun Liu (2016) Experimental research on seismoelectric effects in sandstone. Applied Geophysics 13: 425-436.

11. Djuraev U, Jufar S R, Vasant P (2017) Numerical Study of frequency-dependent seismo electric coupling in partially saturated porous media. MATEC Web of Conferences 87: 02001.

12. Alkhidir KEME (2020) Seismo Magnetic Moment Fractal Dimension for Characterizing Shajara Reservoirs of the PermoCarboniferous Shajara Formation, Saudi Arabia World Scientific News 139: 186-200.

13. Alkhidir KEME (2019) Seismo Diffusion Coefficient Fractal Dimension for Characterizing Shajara Reservoirs of the Permo-Carboniferous Shajara Formation, Saudi Arabia. Research Journal of Nano science and Engineering 3: 23-29.

14. Alkhidir KEME (2019) Molar Enthalpy Fractal Dimension for Characterizing Shajara Reservoirs of the PermoCarboniferous Shajara Formation. Journal of Agriculture and Aquaculture 1: 1-8.

15. Alkhidir KEME (2019) Work Fractal Dimension for Characterizing Shajara Reservoirs of the PermoCarboniferous Shajara Formation, Saudi Arabia. International Journal of Environment \& Agricultural Science 3: 1-8.

16. Alkhidir KEME (2018) Electro Kinetic Fractal Dimension for Characterizing Shajara Reservoirs of the Shajara Formation. International Journal of Nanotechnology in Medicine \& Engineering 3: 54-60.

17. Al-Khidir KE (2018) On Similarity of Pressure Head and Bubble Pressure Fractal Dimensions for Characterizing Permo-Carboniferous Shajara Formation, Saudi Arabia. Journal of Industrial Pollution and Toxicity 1: 102.

Copyright: (C2020 Elameen Alkhidir KEM. This is an open-access article distributed under the terms of the Creative Commons Attribution License, which permits unrestricted use, distribution, and reproduction in any medium, provided the original author and source are credited. 